\title{
Metastability in drowning-out crystallisation: precipitation of highly soluble sulphates
}

\author{
C.M. Pina ${ }^{\mathrm{a}, *}$, L. Fernández-Díaz ${ }^{\mathrm{b}}$, M. Prieto ${ }^{\mathrm{c}}$, S. Veintemillas-Verdaguer ${ }^{\mathrm{d}}$ \\ a Institut für Mineralogie, Universität Münster, Corrensstraße 24, D-48149 Münster, Germany

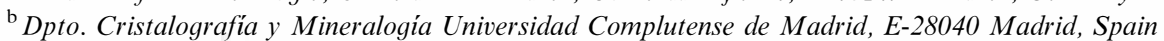 \\ ${ }^{\mathrm{c}}$ Dpto. Geología, Universidad de Oviedo, E-33005 Oviedo, Spain \\ ${ }^{\mathrm{d}}$ Instituto de Ciencia de Materiales de Madrid, C.S.I.C., Cantoblanco, E-28049 Madrid, Spain
}

\begin{abstract}
In this paper we derive equations for evaluating the supersaturation, $\beta$, and the supersaturation rate, $R_{\beta}$, for the drowning-out crystallisation under isothermal conditions and assuming a constant rate of the addition of the co-solvent. Such equations are applied to the drowning-out crystallisation of single and double sulphates in the $\mathrm{M}_{2} \mathrm{SO}_{4}-$ $\mathrm{LiSO}_{4}-\mathrm{H}_{2} \mathrm{O}(\mathrm{M}=\mathrm{Na}, \mathrm{Rb})$ ternary systems. A linear relationship between $\ln R_{\beta}$ and $\ln \beta_{\max }$, similar to that reported for the crystallisation by cooling, evaporation and chemical reaction, has been found.
\end{abstract}

Keywords: Nucleation kinetics; Metastability; Sulphates; Drowning-out; Supersaturation

\section{Introduction}

The crystallisation by evaporation and cooling from aqueous solutions are two of the most extensively used methods in chemical and pharmaceutical industries. However, there exist alternative techniques for the case of crystallisation of some pharmaceutical products, dye stuffs and biological molecules. Among these techniques the precipitation by drowning-out can be considered as one of the most important, especially when the separation of solutes from multicomponent solutions is required [1]. In such a method supersaturation is generated by adding specific substances to the initial solution in order to reduce the solubility of the solute. These substances can be solids, liquids or gases and they are usually called drowning-out (or salting out) agents or precipitants. When the precipitant is a liquid (the most frequent

\footnotetext{
*Corresponding author. Fax: + 49-2-51-83-383-97.

E-mail address: pina@nwz.uni-muenster.de (C.M. Pina).
} 
case) the terms secondary solvent, anti-solvent or co-solvent are employed. The drowning-out crystallisation of highly water-soluble ionic solids is normally induced by adding organic co-solvents miscible in water, such as monovalent alcohols (methanol, ethanol), acetone and other hydrocarbons. They modify the structure, properties and behaviour of the electrolytic solutions, leading to changes in the mobility and solvation of ions [2]. The mixing of solvents has an important effect on dielectric constant, $\varepsilon$, of the solution. The value of $\varepsilon$ for pure water is 80 , while for methanol (one of the most common co-solvent used in drowning-out crystallisation) it is 32.6. According to Bjerrum (1926) [3], the decrease of $\varepsilon$ in waterco-solvent mixtures correlates to the increase of the electrostatic interaction between ions of opposite charge. This favours ionic association and the formation of insoluble ionic species. For each $\varepsilon$ value, there is a critical distance, $\boldsymbol{d}_{\mathrm{c}}$, for which the electrostatic interaction energy (the work required to separate two opposite charges from $\boldsymbol{d}_{\mathrm{c}}$ to the infinity) equals the mean kinetic energy of the charged ions. Below $\boldsymbol{d}_{\mathrm{c}}$, ions cannot be separated by thermal agitation and they form ionic pairs. When $\varepsilon$ is lower than 40 , the formation of ionic pairs generally forms throughout the solution. Therefore, the progressive addition of methanol (or another organic co-solvent) to an aqueous solution of an ionic salt leads to an increase of ionic cohesion forces and eventually precipitation will occur.

Although the crystallisation by drowning-out exhibits clear similarities with the crystallisation by evaporation (it is frequently called "chemical evaporation"), some important differences can be pointed out. Probably, the most important is the continuous increase of the solution volume during the process of drowning-out. This has a strong influence on the nucleation kinetics, resulting in wider metastability zones and changes in the size distribution and morphologies of the crystals. Moreover, the precipitation by drowning-out is very sensitive to operational conditions, such as co-solvent addition rate, stirring rate, experimental set-up geometry and, particularly, to the nature of the co-solvent.

In order to obtain a better understanding of drowning-out crystallisation, it is essential to evaluate how the supersaturation is created in the system, as well as to determine the width of the metastability zones as a function of the supersaturation rate, i.e., the rate at which the system moves from equilibrium.

In this paper we derive expressions for calculating supersaturation and supersaturation rate in an isothermal drowning-out system, where the addition rate of co-solvent is assumed to be constant. These equations are applied to the study of the nucleation behaviour of single and double sulphates in the $\mathrm{M}_{2} \mathrm{SO}_{4} \mathrm{LiSO}_{4} \mathrm{H}_{2} \mathrm{O}(\mathrm{M}=\mathrm{Na}, \mathrm{Rb})$ ternary systems at $50^{\circ} \mathrm{C}$ and using methanol $\left(\mathrm{CH}_{3} \mathrm{OH}\right)$ as co-solvent. The experimental results obtained confirm the general relationship between supersaturation rate and width of the metastable zone, i.e., $\ln \boldsymbol{R}_{\beta} \propto \ln \boldsymbol{\beta}_{\max }$, and allow us to characterise the drowning-out precipitation behaviour of this family of compounds. Finally, nucleation data are discussed in terms of the nucleation theory.

\section{Description of the crystallisation in drowning-out systems}

\subsection{Solubility}

The knowledge of the equilibrium solubility represents the starting point for any study on crystallisation kinetics. In the case of inorganic solutes dissolved in a mixed solvent the solubility dependence on the solvent composition at a constant temperature can be described by means of second or third degree polynomial with the form

$$
c_{\mathrm{s}}=A \boldsymbol{m}^{3}+B m^{2}+C \boldsymbol{m}+\boldsymbol{D}
$$

where $c_{\mathrm{s}}$ is the weight percent of solute in the solution and $m$ is the weight percent of co-solvent in the total solvent. The parameters $A, \boldsymbol{B}, C$ and $\boldsymbol{D}$ are obtained by fitting the experimental data. 


\subsection{Supersaturation and supersaturation rate}

The supersaturation in a drowning-out system involving an aqueous solution and an organic co-solvent can be expressed by

$$
\beta=c / c_{\mathrm{s}},
$$

where $c$ is the actual concentration of solute in the mixed solvent and $c_{\mathrm{s}}$ is the equilibrium solubility.

The concept of metastability limit (width of the metastable zone) is very often employed in the literature, especially in the field of industrial crystallisation. However, it has not been unequivocally defined. The reason for this mainly lies in the fact that the maximum supersaturation value reached by a given system depends on a number of factors: the nature of the solute and solvent, temperature, stirring and mechanical shocks, the thermal history, the total volume of solution, etc. [4]. This means that the metastability limit is strongly controlled by the boundary and initial conditions. This makes it very difficult to compare data from different experiments. Nevertheless, it is clear that, when supersaturation is time-dependent, the velocity of supersaturation generation determines the maximum supersaturation value that can be reached. For example, when a saturated solution is cooled, the width of the metastable zone depends on the cooling rate. According to Nývlt (1968) [5] a semi-empirical relation for such a dependence can be given as

$$
b\left(\mathrm{~d} c_{s} / \mathrm{d} T\right)=K_{t}\left(\Delta c_{\max }\right)^{*} \text {, }
$$

where $\Delta c_{\max }$ is the maximum absolute supersaturation, $\mathrm{d} c_{\mathrm{s}} / \mathrm{d} T$ represents the variation of the solubility with respect to the temperature and $b$ is the cooling rate. The product $b\left(\mathrm{~d} c_{\mathrm{s}} / \mathrm{d} T\right)$ expresses, therefore, the rate at which the system moves from equilibrium, i.e., the supersaturation rate. Finally, the $K_{v}$ and $w$ are empirical coefficients related to nucleation parameters. The Nývlt expression can be generalised in order to apply to any system with changing supersaturation [6]:

$$
R_{g}=K_{v}^{\prime}\left(\beta_{\max }\right)^{\prime \prime},
$$

where $\boldsymbol{\beta}$ is $C / C_{\mathrm{s}}$ with both concentrations expressed in molarities. In logarithmic form, this expression becomes

$$
\ln R_{\rho}=\ln K_{p}^{\prime}+w^{\prime} \ln \beta_{\max }
$$

where $\boldsymbol{R}_{\boldsymbol{\beta}}=\mathrm{d} \boldsymbol{\beta} / \mathrm{d} t$ is the supersaturation rate, $\boldsymbol{\beta}_{\max }$ is the supersaturation at nucleation time and $K_{v}^{\prime \prime}$ and $w^{\prime}$ are generalised empirical coefficients, which depend on the nature of the crystallisation system considered. In this work, we will evaluate $\boldsymbol{\beta}$ from concentration data expressed in percent units, instead of molarities due to the lack of knowledge of the densities of the solutions. The supersaturations reached during most of the experiments were high enough to use this approximation. Only the nucleation of $\mathrm{Li}_{2} \mathrm{SO}_{4} \cdot \mathrm{H}_{2} \mathrm{O}$ took place at low supersaturation levels. However, in this case the scattering of the experimental points made this source of error is negligible.

By substituting Eq. (1) into the definition of $\boldsymbol{\beta}$ the following supersaturation expression is obtained:

$$
\boldsymbol{\beta}=c /\left(A m^{3}+B m^{2}+C m+\boldsymbol{D}\right) .
$$

In the system considered here the concentration of the drowning-out agent, $m$, is time dependent and it is given by

$$
\boldsymbol{m}(t)=\frac{100(\boldsymbol{a}+R t)}{w+\boldsymbol{a}+\boldsymbol{R} t},
$$

where $w$ and $\boldsymbol{a}$ are the initial solvent and co-solvent weights, respectively, $\boldsymbol{R}$ is the co-solvent addition rate and $t$ is the time. In a similar way, the dependence on time of the solute concentration, $c(t)$, can be 
expressed by

$$
c(t)=\frac{100 s}{s+w+a+R t},
$$

where $s$ is the initial weight of the solute.

Eliminating $t$ from Eqs. (7) and (8) the following expression is obtained:

$$
c(t)=\frac{100 s(100-m(t))}{100 s+100 w-s m(t)} .
$$

By substituting Eq. (9) into Eq. (6) we obtain the supersaturation evolution in the drowning-out system during the addition of co-solvent:

$$
\beta(t)=\frac{100 s(100-m(t))}{(100 s+100 w-m(t) s)\left(D+C m(t)+B m(t)^{2}+A m(t)^{3}\right)} .
$$

The evolution of the supersaturation during the addition at constant velocity of co-solvent in a hypothetical drowning-out system is shown in Fig. 1.

In a drowning-out system an expression for the rate at which the supersaturation is created when a co-solvent is added at constant rate can be obtained differentiating Eq. (9) with respect to time (i.e., supersaturation rate):

$$
\begin{aligned}
R_{\beta}(t)=\frac{\mathrm{d}}{\mathrm{d} t} \beta(t)= & {\left[\frac{-100 s}{H(t) c_{\mathrm{s}}(t)}+\frac{-100 s(100-m(t))\left(-s c_{\mathrm{s}}(t)+H(t)\left(3 A m^{2}(t)+2 B m(t)+C\right)\right)}{H^{2}(t) c_{\mathrm{s}}^{2}(t)}\right] } \\
& \times \frac{100 R P(t)-100 R(a+R t)}{P^{2}(t)},
\end{aligned}
$$

where $H(t)=100 s+100 w-m(t) s, c_{\mathrm{s}}(t)=A m^{3}(t)+B m^{2}(t)+C m(t)+D$ and $P(t)=w+a+R t$.

As Eq. (11) indicates, the addition of a co-solvent at constant rate does not produce a constant supersaturation rate.

By analogy with Eq. (5), for a isothermal drowning-out system a linear relationship between $\ln \beta_{\max }$ and $\ln R_{\beta}$ can be expected.

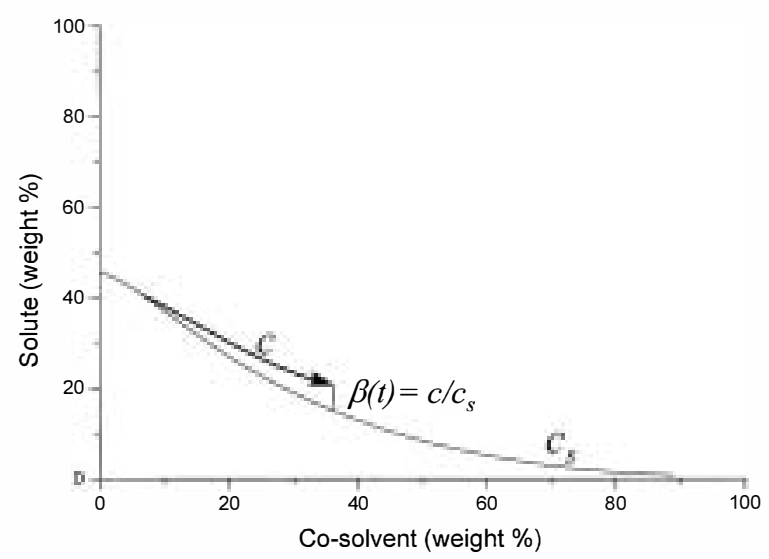

Fig. 1. Evolution of the supersaturation during a hypothetical drowning-out experiment. The arrow shows the variation of the concentration, $c$, and the solid curve represents the solubility curve, $c_{\mathrm{s}}$. The ratio $c / c_{\mathrm{s}}$ gives the supersaturation at any time. 


\section{Experimental procedure}

\subsection{Solubility measurements}

The solubilities of the single sulphates $\mathrm{Na}_{2} \mathrm{SO}_{4}, \mathrm{Rb}_{2} \mathrm{SO}_{4}$ and $\mathrm{Li}_{2} \mathrm{SO}_{4} \cdot \mathrm{H}_{2} \mathrm{O}$, and that of the double sulphates $\beta$ - $\mathrm{LiNaSO}_{4}, \beta^{\mathrm{v}}$ - $\mathrm{LiRbSO}_{4}$ and $\mathrm{Li}_{3} \mathrm{Rb}\left(\mathrm{SO}_{4}\right)_{2} \cdot \mathrm{H}_{2} \mathrm{O}$ in a mixed solvent $\mathrm{H}_{2} \mathrm{O}-\mathrm{CH}_{3} \mathrm{OH}$ have been determined by equilibrating crystals of those compounds with solutions with $\mathrm{CH}_{3} \mathrm{OH} / \mathrm{H}_{2} \mathrm{O}$ ratios ranging from $0 \%$ to $50 \%$. For this purpose a thermostatted solubility cell was used. Temperature was kept constant at $50 \pm 0.2^{\circ} \mathrm{C}$ and mixtures of crystals and solutions were stirred for periods of $18-24 \mathrm{~h}$ in order to ensure saturation. The saturated solutions were chemically analysed by atomic absorption spectrophotometry (UNICAM-SP90). The detection limit for the cations $\mathrm{Li}, \mathrm{Na}$ and $\mathrm{Rb}$ were in the range from 0.001 to $0.05 \mu \mathrm{g} \mathrm{ml}^{-1}$.

\subsection{Drowning-out experiments}

Drowning-out experiments were conducted in a thermostatted crystallisation reactor at $50 \pm 0.2^{\circ} \mathrm{C}$ and at $1 \mathrm{~atm}$ (Fig. 2). For each experiment $100 \mathrm{~cm}^{3}$ of a single or double sulphate saturated aqueous solution was placed into the jacketed beaker of the reactor. Supersaturation was achieved by adding $\mathrm{CH}_{3} \mathrm{OH}$ at a constant rate. In order to evaluate the effect of the supersaturation rate on the nucleation kinetics, a number of experiments using different rates of methanol addition were carried out. The nucleation behaviour was characterised by measuring two parameters: the waiting time, $t_{\mathrm{w}}$, i.e., the time elapsed before nucleation occurred, and the volume of $\mathrm{CH}_{3} \mathrm{OH}$ added at that time. Nucleation was detected when a generalised turbidity was observed in the reactor.

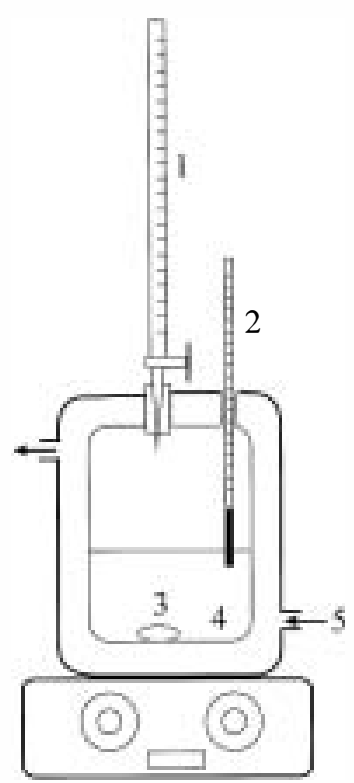

Fig. 2. Thermostatted reactor for conducting drowning-out experiments: (1) Burette for adding $\mathrm{CH}_{3} \mathrm{OH}$, (2) Thermometer, (3) Magnetic stirrer, (4) Solution, (5) Water flux at $50^{\circ} \mathrm{C}$. 

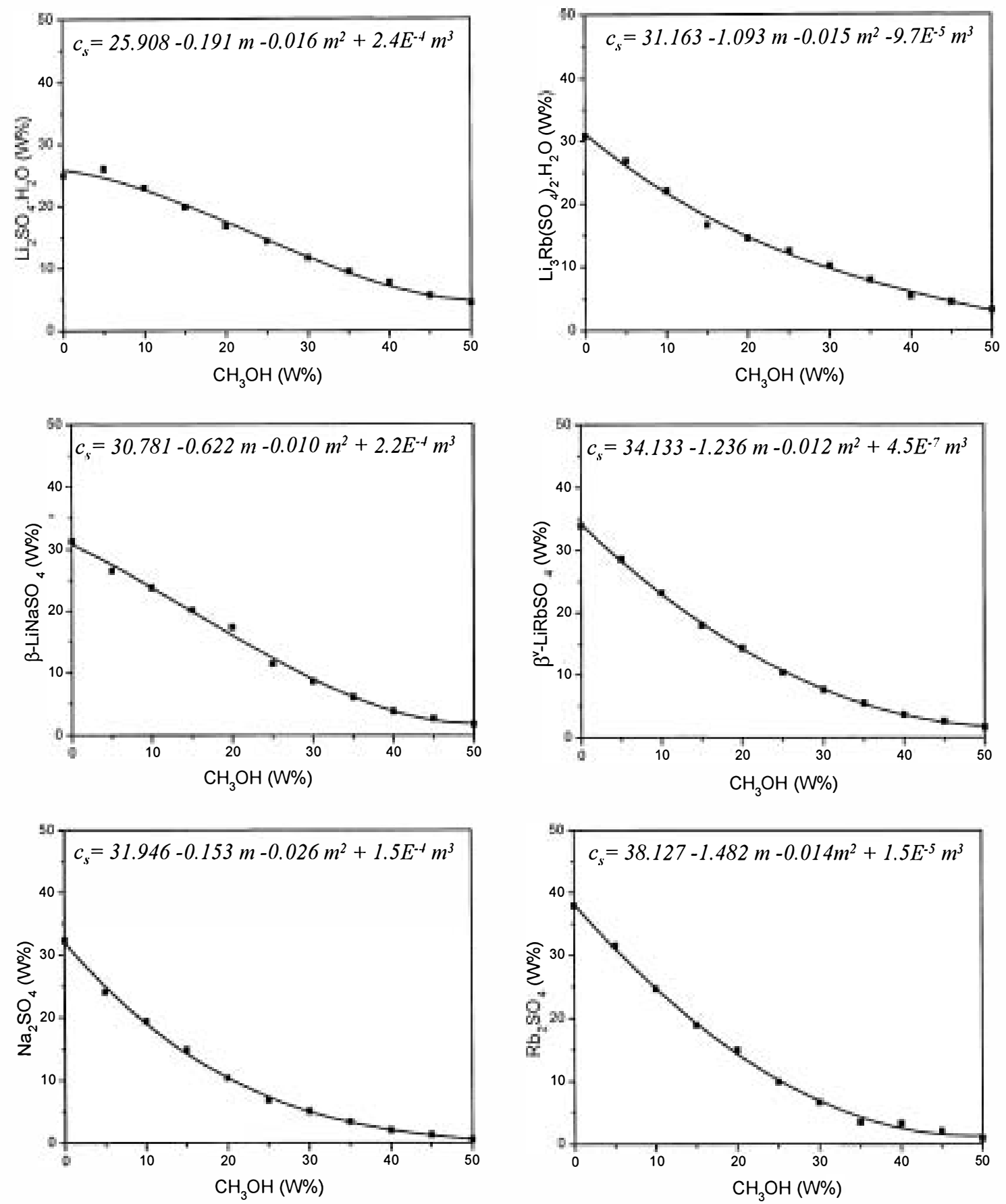

Fig. 3. Solubility curves obtained by fitting experimental data to the third degree polynomial (see Eq. (1)). 
Table 1

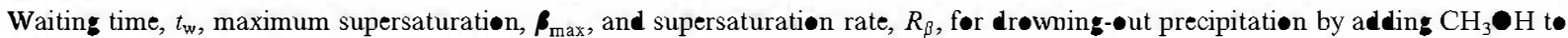
sulphate aque us sølutions at $50^{\circ} \mathrm{C}$ and $1 \mathrm{~atm}$

\begin{tabular}{|c|c|c|c|}
\hline Sulphate & $t_{\mathrm{w}}(\mathrm{s})$ & $R_{f}\left(\mathrm{~s}^{-1}\right)$ & $\boldsymbol{\beta}_{\max }$ \\
\hline$\beta-\mathrm{LiNaSO}_{4}$ & $\begin{array}{l}2.56 \\
2.88 \\
2.77 \\
2.81 \\
1.66 \\
2 \\
2.25 \\
2.38 \\
2.35\end{array}$ & $\begin{array}{l}0.1127 \\
.1153 \\
.1141 \\
.1027 \\
.2109 \\
.1917 \\
.1704 \\
.1612 \\
0.163\end{array}$ & $\begin{array}{l}1.119 \\
1.129 \\
1.119 \\
1.1219 \\
1.159 \\
1.179 \\
1.179 \\
1.180 \\
1.179\end{array}$ \\
\hline $\mathrm{Na}_{2} \mathrm{SO}_{4}$ & $\begin{array}{l}0.63 \\
0.75 \\
0.7 \\
0.89 \\
1.17 \\
2.43 \\
1.24 \\
3 \\
2.68 \\
2.65 \\
1.63 \\
1.59 \\
1.69\end{array}$ & $\begin{array}{l}.421 \\
.6206 \\
.6642 \\
.7310 \\
.6158 \\
.0830 \\
.1117 \\
.081 \\
.0826 \\
.0762 \\
.2052 \\
.2104 \\
0.1982\end{array}$ & $\begin{array}{l}1.155 \\
1.306 \\
1.306 \\
1.434 \\
1.479 \\
1.103 \\
1.038 \\
1.137 \\
1.120 \\
1.103 \\
1.209 \\
1.209 \\
1.21\end{array}$ \\
\hline$\beta^{\mathrm{v}}-\mathrm{LiRbSO}_{4}$ & $\begin{array}{l}1.09 \\
0.91 \\
1.04 \\
1.14 \\
0.88 \\
0.84\end{array}$ & $\begin{array}{l}0.199 \\
0.145 \\
0.502 \\
0.628 \\
0.699 \\
0.732\end{array}$ & $\begin{array}{l}1.091 \\
1.017 \\
1.328 \\
1.465 \\
1.395 \\
1.395\end{array}$ \\
\hline $\mathrm{Rb}_{2} \mathrm{SO}_{4}$ & $\begin{array}{l}1.14 \\
1.5 \\
0.89 \\
0.87 \\
0.74 \\
0.84\end{array}$ & $\begin{array}{l}0.275 \\
0.124 \\
1.085 \\
0.778 \\
1.534 \\
1.149\end{array}$ & $\begin{array}{l}1.173 \\
1.068 \\
1.612 \\
1.431 \\
1.712 \\
1.612\end{array}$ \\
\hline
\end{tabular}



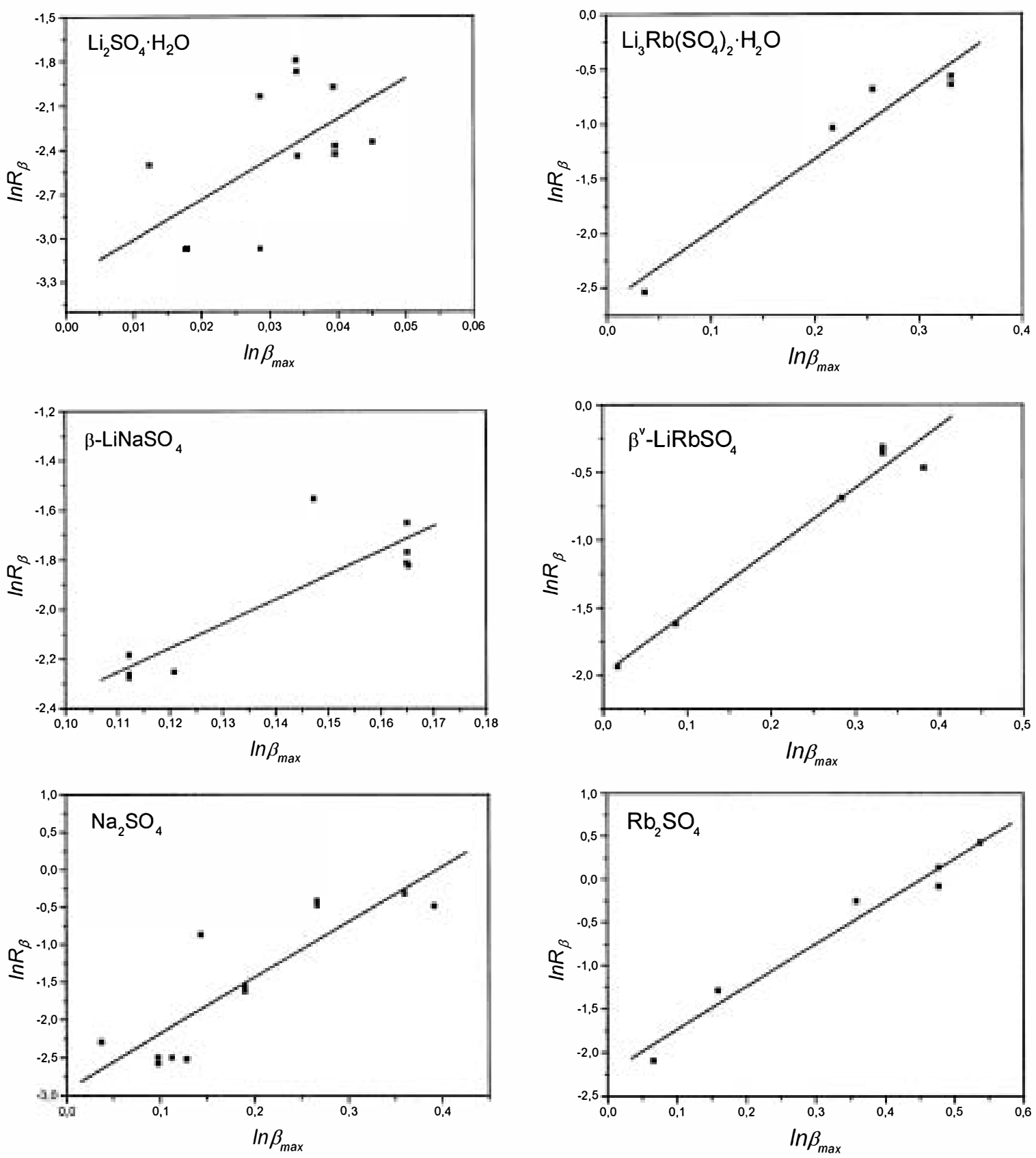

Fig. 4. $\ln R_{\beta}$ versus $\ln \beta_{\max }$ for the $\mathrm{Li}_{2} \mathrm{SO}_{4} \cdot \mathrm{H}_{2} \mathrm{O}, \beta-\mathrm{LiNaSO}_{4}, \mathrm{Na}_{2} \mathrm{SO}_{4}, \mathrm{Li}_{3} \mathrm{Rb}\left(\mathrm{SO}_{4}\right)_{2} \cdot \mathrm{H}_{2} \mathrm{O}, \beta^{\mathrm{v}}-\mathrm{LiRbSO}_{4}$ and $\mathrm{Rb}_{2} \mathrm{SO}_{4}$ crystallising by drowning-out at $50^{\circ} \mathrm{C}$. 


\section{Results and discussion}

\subsection{Solubility curves}

Fig. 3 shows the solubility curves for the $\mathrm{Na}_{2} \mathrm{SO}_{4}, \mathrm{Rb}_{2} \mathrm{SO}_{4} \cdot \mathrm{Li}_{2} \mathrm{SO}_{4} \cdot \mathrm{H}_{2} \mathrm{O}, \beta-\mathrm{LiNaSO}, \beta-\mathrm{LiRbSO}_{4}$ and $\mathrm{Li}_{3} \mathrm{Rb}\left(\mathrm{SO}_{4}\right)_{2} \cdot \mathrm{H}_{2} \mathrm{O}$ salts in mixtures water $/ \mathrm{CH}_{3} \mathrm{OH}$, containing from $050 \%$ of $\mathrm{CH}_{3} \mathrm{OH}$ (in weight percent). These curves have been obtained by fitting experimental data to the third degree polynomial. The fitting was carried out using the mean square method and the correlation coefficients were greater than 0.99 in all the cases.

The sulphates studied here are highly soluble in pure water (their solubilities range from $26 \%$ to $38 \%$ in weight per cent of the total solution). These solubility values are similar to those corresponding to other ionic salts (nitrates, sulphates and chlorides) of alkaline metals and there do not exist appreciable differences between the solubilities of single and double sulphates. The strong decrease of solubility when the methanol/water ratio in the solvent is increased, is also similar for single and double sulphates.

\subsection{Drøwning-॰ut experiments}

From the measurements of waiting time and the volume of $\mathrm{CH}_{3} \mathrm{OH}$ added in each experiment until nucleation in the crystallisation reactor occured, the values of the maximum supersaturation, $\boldsymbol{\beta}(t w)$, and the supersaturation rate, $\boldsymbol{R}_{\boldsymbol{\beta}}(t w)$, can be calculated by using Eqs. (7), (10) and (11). Table 1 summarises the kinetic data for the drowning-out experiments. In Fig. 4 the values of $\ln \boldsymbol{R}_{\beta}$ versus $\ln \boldsymbol{\beta}_{\max }$ have been plotted. As can be seen, in most cases an approximately linear relationship between these two variables is observed, confirming the predictions made in Section 2.2. Table 2 shows that the $K v^{\prime}$ and $w^{\prime}$ are fitting parameters for the six drowning-out system studied. The fitting is relatively poor in the case of $\mathrm{Li}_{2} \mathrm{SO}_{4} \cdot \mathrm{H}_{2} \mathrm{O}, \mathrm{Na}_{2} \mathrm{SO}_{4}$ and $\beta$-LiNaSO 4 , but it can be considered good for the rubidium salts. The following order of increasing metastability can be deduced from the fitting parameters: $\beta^{\mathrm{v}}$-LiRb$\mathrm{SO}_{4} \approx \mathrm{Li}_{2} \mathrm{SO}_{4} \cdot \mathrm{H}_{2} \mathrm{O}<\mathrm{Rb}_{2} \mathrm{SO}_{4}<\mathrm{Li}_{3} \mathrm{Rb}\left(\mathrm{SO}_{4}\right)_{2} \cdot \mathrm{H}_{2} \mathrm{O}<\beta-\mathrm{LiNaSO}_{4}<\mathrm{Na}_{2} \mathrm{SO}_{4}$.

The maximum supersaturation reached in a given system depends on intensive variables as well as on the device used to detect the nucleation phenomenon. However, the relationship between the maximum supersaturation and the rate of supersaturation generation derives from kinetic reasons which are not considered by the classical nucleation theory. Nucleation is preceded by a number of chemical solution processes, each one characterised by its own kinetics. If the system moves from the equilibrium state very fast, intermediate chemical species have no enough time to form in a concentration which allows the crystallisation of the new solid phase. Moreover, in the case of drowning-out crystallisation the increase of volume also reduces the probability of nucleation. Therefore, the faster the movement of the system from

Table 2

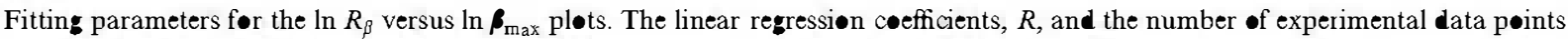
are als• given

\begin{tabular}{|c|c|c|c|c|}
\hline Sulphate & $\ln K_{\mathrm{s}^{\prime}}^{\prime}$ & $\ln w^{\prime}$ & $R$ & $\begin{array}{l}\text { Number } \\
\text { of data }\end{array}$ \\
\hline $\mathrm{Li}_{2} \mathrm{SO}_{4} \cdot \mathrm{H}_{2}$ & $-3.2 \pm 0.3$ & $27 \pm 11$ & 0.59 & 13 \\
\hline$\beta-\mathrm{LiNaSO}_{4}$ & $-3.3 \pm 0.3$ & $9.8 \pm 2$ & 0.87 & 9 \\
\hline $\mathrm{Na}_{2} \mathrm{SO}_{4}$ & $-2.9 \pm 0.3$ & $7.4 \pm 1$ & 0.86 & 13 \\
\hline $\mathrm{Li}_{3} \mathrm{Rb}\left(\mathrm{S}_{4}\right)_{2} \cdot \mathrm{H}_{2}$ & $-2.6 \pm 0.2$ & $6.6 \pm 1$ & 0.97 & 5 \\
\hline $\boldsymbol{\beta}^{\mathrm{V}}-\mathrm{LiRbS}_{4}$ & $-2.0 \pm 0.1$ & $4.6 \pm 0.4$ & 0.98 & 6 \\
\hline $\mathrm{Rb}_{2} \mathrm{SO}_{4}$ & $-2.2 \pm 0.1$ & $4.9 \pm 0.4$ & 0.98 & 6 \\
\hline
\end{tabular}


equilibrium, the higher the supersaturation reached without nucleation. The relationship between supersaturation rate and supersaturation at nucleation onset has the form: $\ln \boldsymbol{R}_{\beta} \propto \ln \boldsymbol{\beta}_{\max }$. This relationship which seems to be universal is independent of the system considered. However, in order to explain differences in metastability, it is interesting to consider one of the most important chemical processes involved in nucleation: the formation of ionic pairs in the solution. In the case of alkaline sulphate aqueous solutions there exist two kinds of chemical species: isolated solvated ions and solvent mediated $\left[\mathrm{M}-\mathrm{H}_{2} \mathrm{O}-\mathrm{SO}_{4}\right]$ ionic pairs [7]. The addition of methanol induces more pairing in the solution via the decrease of the dielectric constant, and eventually the formation of clusters of ions occurs. In the cases considered in this work, the ion pair formed in the solutions involve the chemical species $\mathrm{LiSO}_{4}^{-}$. On entering into a crystal structure the ions release some, or all, of their hydration water. Reich and Kahlweit (1968) [8,9] suggested that the activation energy of growth units integration strongly depends on the energy required for the dissociation of a water molecule from the hydrated ion. We estimated the dehydration energy, using data published by Dzidic and Kebarle (1970) [10] and Ashardi et al. (1970) [11], and assuming that anions are unhydrated, for the following crystallisation reactions:

$$
\begin{array}{ll}
\mathrm{LiSO}_{4}^{-}+\mathrm{Li}\left(\mathrm{H}_{2} \mathrm{O}\right)_{6}^{+} \rightarrow \mathrm{Li}_{2} \mathrm{SO}_{4} \cdot \mathrm{H}_{2} \mathrm{O}+5 \mathrm{H}_{2} \mathrm{O}, & \Delta H_{\mathrm{deh}}=373 \mathrm{~kJ} \mathrm{~mol}^{-1}, \\
\mathrm{LiSO}_{4}^{-}+\mathrm{Rb}\left(\mathrm{H}_{2} \mathrm{O}\right)_{6}^{+} \rightarrow \mathrm{LiRbSO}_{4}+6 \mathrm{H}_{2} \mathrm{O}, & \Delta H_{\mathrm{deh}}=306 \mathrm{~kJ} \mathrm{~mol}^{-1}, \\
2 \mathrm{Rb}\left(\mathrm{H}_{2} \mathrm{O}\right)_{6}^{+}+\mathrm{SO}_{4}^{-} \rightarrow \mathrm{Rb}_{2} \mathrm{SO}_{4}+12 \mathrm{H}_{2} \mathrm{O}, & \Delta H_{\mathrm{deh}}=612 \mathrm{~kJ} \mathrm{~mol}^{-1}, \\
2 \mathrm{LiSO}_{4}^{-}+\mathrm{Li}\left(\mathrm{H}_{2} \mathrm{O}\right)_{6}^{+}+\mathrm{Rb}\left(\mathrm{H}_{2} \mathrm{O}\right)_{6}^{+} \rightarrow \mathrm{Li}_{3} \mathrm{Rb}\left(\mathrm{SO}_{4}\right)_{2} \cdot \mathrm{H}_{2} \mathrm{O}+5 \mathrm{H}_{2} \mathrm{O}, & \Delta H_{\mathrm{deh}}=679 \mathrm{~kJ} \mathrm{~mol}^{-1}, \\
\mathrm{LiSO}_{4}^{-}+\mathrm{Na}\left(\mathrm{H}_{2} \mathrm{O}\right)_{6}^{+} \rightarrow \mathrm{LiNaSO}_{4}+6 \mathrm{H}_{2} \mathrm{O}, & \Delta H_{\mathrm{deh}}=403 \mathrm{~kJ} \mathrm{~mol}^{-1}, \\
2 \mathrm{Na}\left(\mathrm{H}_{2} \mathrm{O}\right)_{6}^{+}+\mathrm{SO}_{4}^{-} \rightarrow \mathrm{Na}_{2} \mathrm{SO}_{4}+12 \mathrm{H}_{2} \mathrm{O}, & \Delta H_{\mathrm{deh}}=806 \mathrm{~kJ} \mathrm{~mol}^{-1}
\end{array}
$$

In principle, the more metastable systems should be characterised by the higher dehydration energies. According to this, the expected order of increasing metastability should be $\beta^{\mathrm{v}}$ - $\mathrm{LiRbSO}_{4} \approx \mathrm{Li}_{2} \mathrm{SO}_{4} \cdot \mathrm{H}_{2} \mathrm{O}<\beta$ $\mathrm{LiNaSO}_{4}<\mathrm{Rb}_{2} \mathrm{SO} 4<\mathrm{Li}_{3} \mathrm{Rb}\left(\mathrm{SO}_{4}\right)_{2} \cdot \mathrm{H}_{2} \mathrm{O}<\mathrm{Na}_{2} \mathrm{SO}_{4}$. As can be seen, with the exception of $\beta-\mathrm{LiNaSO}_{4}$, this sequence coincides with the experimentally observed. Therefore, it can be concluded that, when ion pairs are taken into account, the dehydration energy strongly controls metastability in drowning-out systems. In addition metastability can be described by a linear relationship between $\ln \boldsymbol{R}_{\beta}$ and $\ln \boldsymbol{\beta}_{\max }$.

\section{Acknowledgements}

The authors acknowledge A. Putnis for critical reading of the manuscript. This work was partially supported by CYCIT (Science and Technology Commission of Spain), grant MAT 90-0775-CO3-03, and by the German/Spanish Joint Research Programme (Acción Integrada HA1997-0126). C.M. Pina acknowledges the receipt of a Marie Curie Fellowship from the European Commission.

\section{References}

[1] L. Ata, Z.B. Alfassi, Sep Sci. Techn॰1. 21 (1986) 655.

[2] R.J. Davey, J. Crystal Grøwth 76 (1986) 637.

[3] N. Bjerrum, Danske vidensk, Selks, 1926, 'Selected papers' 9, 1949 in Einar Munsksaard, Cøenhazen.

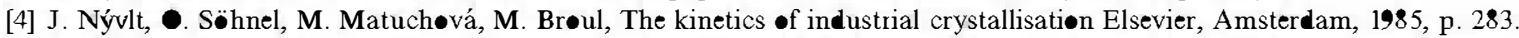

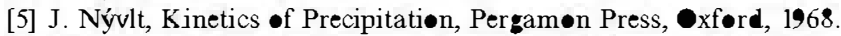

[6] M. Priet•, A. Putnis, L. Fernández-Díaz, S. Løpez Andrés, J. Crystal Grøwth 142 (1994) 225. 


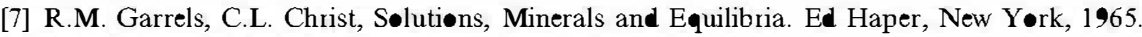

[8] R. Reich, M. Kahlweit, Ber. Busenges. 72 (1968) 66.

[9] P. Bennema, J. Crystal Grøwth 1 (1967) 287.

[10] I. Dzidic, P. Kebarle, J. Phys. Chem. 74 (1970) 1466.

[11] M. Ashardi, R. Yamdagni, P. Kebarle, J. Phys. Chem. 74 (1970) 1475. 